\title{
A Theoretical Inquiry of the Offset Mechanism in Mitigating Global Warming: Economic Welfare Implications of the Clean Development Mechanism Investment
}

\author{
Morio Kuninori ${ }^{1} \&$ Masayuki Otaki ${ }^{2}$ \\ ${ }^{1}$ Faculty of Sustainability Studies, Hosei University, Tokyo, Japan \\ ${ }^{2}$ The Institute of Social Sciences, The University of Tokyo, Tokyo, Japan \\ Correspondence: Morio Kuininori, Faculty of Sustainability Studies, Hosei University, 2-17-1, Fujimi, Chiyoda- \\ ku, Tokyo, Japan. E-mail: kuninori@hosei.ac.jp
}

Received: December 27, 2016

Accepted: February 11, 2017

Online Published: February 27, 2017

doi:10.5539/enrr.v7n1p76

URL: http://dx.doi.org/10.5539/enrr.v7n1p76

\begin{abstract}
This study attentively examines the role of the offset mechanism like the Clean Develop Mechanism (CDM) in mitigating global warming problems and considers its economic welfare implications in a theoretical offset environment. The CDM is a kind of offset trading scheme of carbon dioxide $\left(\mathrm{CO}_{2}\right)$ emissions between advanced and developing economies. Formulating the essence of the offset market into a simple model, we interpret the right to trade $\mathrm{CO}_{2}$ emissions at an ideal price as rewards to advanced economies for investing in more $\mathrm{CO}_{2}$ saving technologies and/or factories in developing economies. Our model shows that under some conditions the CDM can succeed in suppressing $\mathrm{CO}_{2}$ emissions and become a second-best measure to mitigate global warming. Nevertheless, we also clarify that the prices of carbon offset in advanced economies are not generally sustainable without the help of the outside agencies such as the governments. This fact suggests that offset mechanism like the CDM incurs an additional burden, such as taxes to advanced economies for preserving the scheme, although the resultant transfer evidently equalizes the international income distribution.
\end{abstract}

Keywords: Offset mechanism, Clean Development Mechanism, global warming problem, additionality, baseline

\section{Introduction}

Whether the Clean Development Mechanism (CDM) under the Kyoto Protocol substantially mitigates the excess $\mathrm{CO}_{2}$ emissions is quite obscure. This is not merely because the structure of the CDM scheme is rather complicated to understand, but also because the offset trading system does not seem to reduce total $\mathrm{CO}_{2}$ emissions in reality. This study offers a simple model of an offset mechanism like the CDM scheme that captures its important characteristics and analyzes the economic welfare implications of this scheme (Hereafter, we call an offset mechanism as the CDM since the CDM scheme carries most of the offset characteristics we want to deal with).

The carbon market under the $\mathrm{CDM}$ scheme trades reduction credits of $\mathrm{CO}_{2}$ emissions originating from nascent and/or prevailing emission-saving technology in developing economies (Note 1). This study clarifies that the CDM contributes to mitigating excess emissions of $\mathrm{CO}_{2}$ as long as the carbon price is set properly, following the modified Samuelson rule (Note 2). In addition, since the CDM presumes voluntary transactions, it is apparent that developing economies becomes better off by joining this scheme. That is, if it works, the CDM could achieve mitigation of income disparity between advanced and developing economies.

The second concern of this study is the income redistribution effect of the CDM scheme. There is no object that designates proper carbon price in the $\mathrm{CDM}$ scheme in itself. Accordingly, a kind of rationing of allowable $\mathrm{CO}_{2}$ emissions to each firm is unavoidable if one considers that the control of $\mathrm{CO}_{2}$ emissions is effective. Nevertheless, as long as the actualized aggregate emissions of advanced economies stay within the amount of the acquired reduction credit by the CDM, the price of carbon cannot remain at ideal levels. As such, the economic value of the carbon credit is heavily impaired. This makes the CDM scheme dysfunctional. If the governments of advanced economies intend to sustain a suitable positive carbon price, the governments, by themselves, must intervene in the market, by purchasing the corresponding amounts of reduction credits. 
Because government expenditure is ultimately financed by tax, such purchases redistribute incomes from tax payers unrelated to the CDM scheme to participants. While one could encounter many difficulties in judging the fairness on income distribution, it should be noted acutely that debt finance is undesirable because this disturbs the income distribution of future generations who are not responsible for the state of current economies. Thus, it is quite important where to set the baseline of the CDM scheme that is the reference point that determines the volume of tax credit of $\mathrm{CO}_{2}$ emissions. This study also analyzes this problem.

The rest of this study is organized as follows. Section 2 constructs a static model of $\mathrm{CO}_{2}$ emissions control by the CDM scheme and shows that the CDM can enhance wellbeing in both an advanced economy and a developing economy. Section 3 explains the income redistribution effect associated with our CDM model, and discusses the role of the carbon finance alongside the trade of emissions rights. Section 4 provides brief concluding remarks.

\section{The Model}

\subsection{The Laissez-Faire Economy}

As a reference case, let us consider the laissez-faire world economy in which there is no regulation on $\mathrm{CO}_{2}$ emissions and emission decisions are segregated from the calculation of associated damages. It is assumed that there are $n$ economies of type $k(k=a, d: a$ and $d$ refer to advanced and developing economies, respectively). Let the economic benefits of an economy be denoted by $\alpha F\left(e_{i}^{k}\right)$, where $e_{i}^{k}$ is the volume of emissions of the $i$-th economy of type $k . \alpha$ is a parameter that represents the efficiency of the fossil fuel combustion. Figure 1 illustrates the shape of the function $F\left(e_{i}^{k}\right)$. It should be noted that it is assumed there is an upper limit of the benefits from the combustion for a given $\alpha$ (i.e., $\alpha F(\bar{e})$ ).

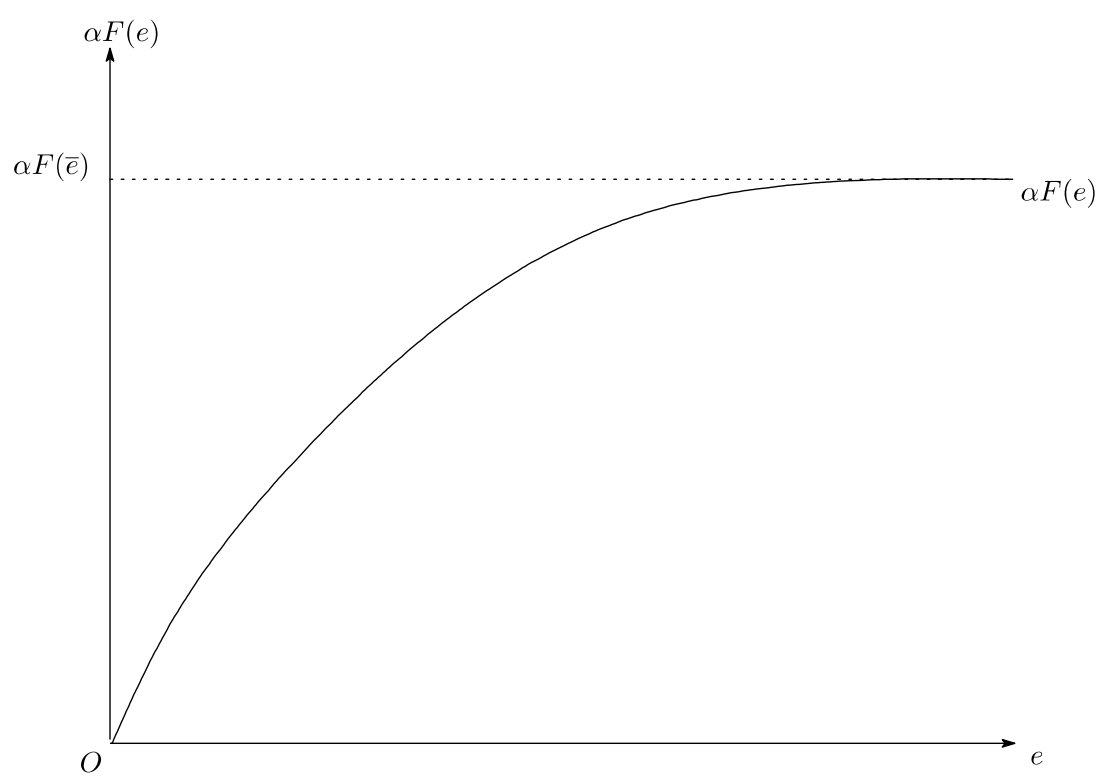

Figure 1. The production function

For simplicity, the damage function $\Psi$ of global warming for an economy via fossil fuel combustion is assumed to be the same linear homogenous quasi-convex, non-negative, strictly increasing and symmetric function denoted

$$
\Psi\left(\cdot, e_{l}^{k}, \cdots, e_{l^{\prime}}^{k^{\prime}} \cdot \cdot\right) \equiv \Psi\left(\cdot, e_{l^{\prime}}^{k^{\prime}}, \cdots, e_{l}^{k} \cdot \cdot\right), \forall k, k^{\prime}, l, l^{\prime} .
$$

The symmetry represented in Equation (1) implies that the damages of global warming are unrelated to the locations where $\mathrm{CO}_{2}$ is emitted.

Since the emissions decisions are assumed to be segregated, the maximal emissions $\bar{e}$ are actualized in the laissez-faire economy. Consequently, the resultant welfare of an economy is

$$
\alpha F(\bar{e})-\Psi(\bar{e}, \bar{e}, \cdots, \bar{e}, \cdots, \bar{e}, \bar{e}) .
$$




\subsection{Economic Welfare under the CDM Scheme}

This subsection examines whether economic welfare is improved by applying the CDM scheme to a pair of one advanced and one developing economy where both economies are in laissez-faire situation. This study captures the CDM scheme as follows.

(i) $\varepsilon$ units of goods are required for capital investment in a developing country. Which of the two economies finance the associated fund is not essential for evaluating the economic welfare as is discussed in Section 3 .

(ii) If and only if the capital investment is additional (the term additional is strictly defined below), the project is certified.

(iii) Such a certified investment is rewarded by an emission right whose value is $\theta[\hat{e}-e] . \theta$ denotes the unit carbon price that is designated by governments. $\hat{e}$ is the baseline of emissions associated with this investment, and $e$ represents the actual emissions.

(iv) Whenever the carbon market falls into disequilibrium, the government of the advanced economy bridges the gap (Note 3). The necessary funds for this compensation are financed by taxes in the advanced economy.

The sum of the gains obtained by applying the CDM scheme of the $i$-th pair of advanced and developing economies is written as

$$
\alpha F\left(e_{i}^{a}\right)+\alpha F\left(e_{i}^{d}\right)-2 \Psi\left(e_{1}^{a} \cdot \cdot e_{i}^{a} \cdot \cdot e_{n}^{a}, e_{1}^{d} \cdot \cdot e_{i}^{d} \cdot \cdot e_{n}^{d}\right)-\varepsilon .
$$

Equation (3), which is fundamental in our model, becomes the objective function of the CDM scheme. One must note that the transaction amount of the emissions right, $\theta\left[\hat{e}-e_{i}^{d}\right]$, does not appear in Equation (3). This is because the carbon market between an advanced and a developing country functions only as an income transfer mechanism and does not relate to efficient carbon allocation although such an amount is vital for capital investment to become additional in the CDM scheme.

While the conditions for additionality under the actual CDM scheme are very complicated and there are many requirements in reality, this study focuses on the following two properties.

\section{Definition 1.}

A plan to invest capital in a developing economy is additional whenever the following two conditions are satisfied.

(i) Financially additional: the investment is feasible in that the direct benefits from emissions trading are privately beneficial and the revenues from the trading, $\theta[\hat{e}-e]$, exceeds the associated $\operatorname{cost} \varepsilon$. That is, the following should hold (Note 4):

$$
\theta\left[\hat{e}-e_{i}^{d}\right] \geq \varepsilon
$$

(ii) Socially additional: the maximized value of social welfare function (3) takes a larger value than that in the state of laissez-faire defined by Equation (2).

Condition (i) prescribes that the capital investment should be compatible with the private motive. Condition (ii) requires that the CDM scheme should enhance the economic wellbeing of the conjoining two economies in reality.

The problem to be solved in this subsection is to maximize Equation (3) on $\left(e_{i}^{a}, e_{i}^{d}\right)$ under the constraint of Equation (4). One must also ascertain whether the maximized value satisfies the requirement of being socially additional (Condition (ii) in Definition 1). For the first step, the following lemma is used.

\section{Lemma 1.}

For any fixed $\theta\left[\hat{e}-e_{i}^{d}\right]$, there is a sufficiently small $\varepsilon$ that satisfies Equation (4). Conversely, for any fixed $\varepsilon$, there is a sufficiently large $\hat{e}$ that satisfies Equation (4).

Lemma 1 implies that the constraint in Equation (4) becomes redundant as long as the investment cost $\varepsilon$ is sufficiently small relatively to the benefits obtained from trading emissions rights, and this is attainable by setting the baseline $\hat{e}$ to be high enough. Since the baseline $\hat{e}$ is directly unrelated to the maximization problem in Equation (3), we can separate the maximization problem from the decision of where to set the baseline $\hat{e}$.

Accordingly, the necessary and sufficient condition for the maximization of the social utility function in Equation (3) becomes

$$
\alpha F^{\prime}\left(e_{i}^{a}\right)=2 \frac{\partial \Psi}{\partial e_{i}^{a}}, \alpha F^{\prime}\left(e_{i}^{d}\right)=2 \frac{\partial \Psi}{\partial e_{i}^{d}}, \forall i
$$

By the symmetry assumption in Equation (1), we obtain 


$$
\frac{\partial \Psi}{\partial e_{i}^{a}}=\frac{\partial \Psi}{\partial e_{i}^{d}}=\frac{\partial \Psi}{\partial e_{1}^{a}}, \quad \forall i
$$

Substituting Equation (6) into (5), it is ascertained that

$$
\alpha F^{\prime}\left(e_{i}^{k}\right)=\alpha F^{\prime}\left(e^{*}\right)=2 \frac{\partial \Psi}{\partial e^{a}}, \quad \forall k, i
$$

Since the right-hand side of Equation (7) represents the social marginal cost of $\mathrm{CO}_{2}$ emissions, the price of carbon $\theta$ should be determined at the level of $\theta^{*}$. That is,

$$
\theta^{*}=2 \frac{\partial \Psi}{\partial e_{1}^{a}}
$$

Equation (8) implies that the price of carbon should be equal to the sum of the marginal nuisance of the emissions of the economies that are partners in the CDM scheme. This is a form of Samuelson's (Samuelson, 1954) rule in the sense that the price of public bads (goods) should be determined by the sum of marginal disutility (utility) of sufferers (beneficiaries).

As discussed above, we confirm that the capital investment satisfies the condition (i) for additionality if $\mathcal{E}$ is small enough, and that the carbon price subdues the rule in Equation (8). Finally, what remains to check is whether the resource allocation designated by the rule in Equation (8) is consistent with condition (ii) in Definition1.

Concerning this question, the following theorem holds.

\section{Theorem 1.}

Since

$$
\alpha F\left(e^{*}\right)-\Psi\left(e^{*} \cdot \cdot e^{*} \cdot \cdot e^{*}, e^{*} \cdot \cdot e^{*} \cdot \cdot e^{*}\right)>\alpha F(\bar{e})-\Psi(\bar{e} \cdot \bar{e} \cdot \bar{e}, \bar{e} \cdot \cdot \bar{e} \cdot \bar{e}),
$$

the $\mathrm{CDM}$ scheme that satisfies Equation (7) improves economic welfare in both advanced and developing countries in comparison with the laissez-faire state in Equation (2).

Proof. Because $\alpha F-\Psi$ is strictly concave and $\alpha F^{\prime}(\bar{e})-\left.n \frac{\partial \Psi}{\partial e_{1}^{a}}\right|_{e_{1}^{a}=\bar{e}}=-\left.n \frac{\partial \Psi}{\partial e_{1}^{a}}\right|_{e_{1}^{a}=\bar{e}}<0, e^{*} \neq \bar{e}$.

Accordingly, (9) holds. If $\varepsilon$ is sufficiently small, $\varepsilon$ exists such that

$$
\alpha F\left(e^{*}\right)-\Psi\left(e^{*} \cdot \cdot e^{*} \cdot \cdot e^{*}, e^{*} \cdot \cdot e^{*} \cdot \cdot e^{*}\right)-\varepsilon>\alpha F(\bar{e})-\Psi(\bar{e} \cdot \bar{e} \cdot \bar{e}, \bar{e} \cdot \cdot \bar{e} \cdot \bar{e}) .
$$

Equation (10) implies that economic welfare in both economies is improved by the CDM regardless of which economy has incurred expense for the capital investment, as long as the investment costs are not so expensive. QED.

Consequently, it has been ascertained that the CDM scheme that obeys optimal carbon pricing rule (8) satisfies the conditions for capital investment additionality in the sense of Definition 1.

\section{Determination of the Baseline and Associated Change of Income Distribution}

\subsection{Relationship between the Baseline and Domestic Income Distribution}

The discussion about the CDM scheme in Section 2 neglects the income redistribution effect into the domestic economies. This is because the determination of the baseline $\hat{e}$ is not concerned with the optimal emissions allocation, and relates only to the income redistribution in conjunction with the achievement of the CDM scheme. This section deals with how the level of $\hat{e}$ affects income distribution within an advanced economy. While trading in emissions rights is limited to the bilateral case, the essence of the discussion is also applicable to the case of the international and open market in which an economy in excess supply of the emissions rights exports its rights to economies with excess demand for such rights.

Excess supply emerges in an economy when $\hat{e}$ is located at

$$
\theta^{*}\left[\hat{e}-e^{*}\right]>\theta^{*} e^{*}
$$

The left-hand side of Equation (11) is the supply of the emissions right that is obtained from the emissions-saving capital investment for a developing economy. The right-hand side is the demand for the emissions right of the domestic industry. Insofar as Inequality (11) is maintained, the emissions right market cannot sustain the carbon price in market $\theta$ at the designated price $\theta^{*}$ because of the existence of excess supply, which amounts to $\theta^{*}\left[\hat{e}-2 e^{*}\right]$.

Such an amount of emissions right may well be purchased by the government in order to sustain the equilibrium market price at $\theta^{*}$. Because the government expenditure is financed by taxation, $\theta^{*}\left[\hat{e}-2 e^{*}\right]$ amounts of income, 
which corresponds to the subsidy paid for participating in the CDM scheme, are transferred from unrelated (taxed) individuals to the participants of the CDM scheme within the advanced economy. Thus, the baseline, $\hat{e}$, acutely affects the income distribution within the advanced economy. While employers are encouraged to participate into the CDM scheme by an increase in the baseline, $\hat{e}$, the associated costs are burdens for other taxpayers.

Thus, the evaluation of income redistribution is quite a difficult problem. There is, at least, one thing of which to be cautious. Since $\mathrm{CO}_{2}$ emissions remain in the atmosphere over time and aggravate the standard of living of our descendants, the associated costs for encouraging the CDM scheme should be levied not from future generations but from the present generation. This is because only direct taxation from the present generation could warn a legitimate price for which they should pay for their own emissions. In this sense, debt finance for the subsidy is prohibitive since this procedure is accompanied by no pain to the present generation.

\subsection{Carbon Financing and Government Intervention}

In this subsection, the function of carbon finance is formatted and reveals the necessity for the government intervention analyzed in the subsection 3.1. Carbon finance in this study is regarded as a type of finance in which money is lent to a developing economy for a capital investment in emissions-saving technology and/or factories in exchange for the trade in those emissions savings.

Accordingly, the first condition for the capital investment being additional, that is, Inequality (4), is equivalent to the viability condition of such finance. Thus, to make financial intermediaries confident in the result of carbon financing, the confidence in the government's intervention to equilibrate the carbon market at the designated price $\theta^{*}$ must be acutely decisive. As such, carbon finance is a fragile concern without government help, as depicted by Lovins and Cohen (2011, p. 227).

\section{Concluding Remarks}

In a highly simplified offset scheme, this study designates the CDM as an acquisition mechanism of carbon credits for returns from emissions-saving capital investments in developing economies, which are conditional on additionality. The requirements for a project to be additional are defined clearly.

It should be noted that our theory is also applicable to the case in which a developing country constructs an emissions-saving facility and sells the acquired carbon credits to an advanced economy.

This is because the difference between the former and the latter case is only the difference to who owns the property rights of the emissions-saving capital and associated carbon credits. In the former case, these property rights belong to the advanced economy, and the converse is true in the latter. By the Coase theorem (Coase, 1960), the efficient allocation of public goods (bads) through a bargaining process is achievable without conferring the location of property rights. Therefore, our model is also applicable to the case in which a developing economy directly accesses the CDM scheme (Note 5).

This study also finds that the optimal carbon price, which should be designated in the carbon market, is the sum of the marginal disutility of the two economies derived from $\mathrm{CO}_{2}$ emissions. This is a variant of Samuelson rule concerning the allocation of public goods (bads).

Finally, the role of the baseline is discussed in conjunction with the role of the government intervention to equilibrate the carbon market under the designated price. Whenever the baseline is set above the equilibrium transaction volume, an excess supply of carbon credits appears, and the government purchases such residues in order to sustain the designated price. Such purchases subsidize and enhance the CDM projects but ultimately become the burdens of taxpayers who are unrelated directly to the CDM projects. Thus, we find that the location of the baseline from the viewpoint of economics strongly related to the income redistribution problem provoked by CDM projects.

\section{References}

Brohé, A. (2014). Whither the CDM? Investment outcomes and future prospects. Environment, Development and Sustainability, 16, 305-322. https://doi.org/10.1007/s10668-013-9478-5

Coase R. (1960). The problem of social cost. Journal of Law and Economics. 3(1), 1-44. https://doi.org/10.1086/ 466560

Lovins, L. H., \& Cohen, B. (2011). Climate capitalism: Capitalism in the age of climate change. New York, NY: Hill and Wang.

Mas-Colell A., Whinston, M. D., \& Green, J. R. (1995). Microeconomic theory. New York, NY: Oxford University Press. 
Samuelson, P. A. (1954). A pure theory of public expenditure. Review of Economic Statistics, 36(4), 387-389. https://doi.org/10.2307/1925895

Schneider, L. (2009). Assessing the additionality of CDM projects: Practical experiences and lessons learned. Climate Policy, 9(3), 242-254. https://doi.org/10.3763/cpol.2008.0533

United Nations Framework Convention on Climate Change. (2012). TOOL01, Methodological tool: Tools for the demonstration and assessment of additionality (Ver. 07.0.0). Retrieved from https://cdm.unfecc.int/ methodologies/PAmethodologies/tools/am-tool-01-v7.0.0.pdf

United Nations Framework Convention on Climate Change. (2014). CDM Methodology Booklet (6th Ed., Information Updated as of EB 79, November). Retrieved from https://cdm.unfccc.int/methodologies/ Documentation/1411/Meth_Booklet_2014_Named.pdf

\section{Notes}

Note 1. Typical types of actual CDM projects and their methodologies are explained in United Nations Framework Convention on Climate Change [UNFCCC] (2014).

Note 2. It is often stated that an offset mechanism does not generate additional carbon reduction globally (e.g. Brohé, 2014). It should be noted, however, that appropriate carbon pricing enables the total carbon reduction worldwide in our model.

Note 3. In our model, the market consists of only carbon credits from the CDM scheme in order to highlight the offset mechanism.

Note 4. This is a half of the notion of additionality. The other half indicates that, without the CDM project, the capital investment must not be feasible. Since most of the profitable investment projects would be feasible even without the revenue from the CDM project, additionality condition rules out these profitable projects. Although UNFCCC has been trying to satisfy the additionality condition, issuing methodological tools such as UNFCCC (2012), various studies, including Schneider (2009), have claimed that many CDM projects often fail to pass the additionality test, thereby, losing the "environmental integrity" of the CDM credit program. In our study, one of the sufficient conditions of additionality may be expressed as $\alpha F\left(e_{i}^{d}\right)<\varepsilon$. However, hypothetically speaking, there would be other kinds of barriers in preventing the project when the revenue is unavailable. Some of the barriers are discussed in UNFCCC (2012).

Note 5. See Mas-Colell, Whinston, and Green (1995, pp. 356-357) for a concise explanation about the Coase theorem.

\section{Copyrights}

Copyright for this article is retained by the author(s), with first publication rights granted to the journal.

This is an open-access article distributed under the terms and conditions of the Creative Commons Attribution license (http://creativecommons.org/licenses/by/4.0/). 